\title{
Energy efficiency of the accumulation wall with a transparent insulation
}

\author{
Jadwiga Świrska-Perkowska*, and' Karolina Jęglet \\ Opole University of Technology, Faculty of Civil Engineering and Architecture, 45-061 Opole, \\ Katowicka 48, Poland
}

\begin{abstract}
This paper presents a numerical model of an accumulating solar wall with transparent insulation (ASW-TI). The objective of the simulation was to evaluate the energy efficiency of ASW-TI for different climatic conditions in Poland, i.e. for high, medium, and low irradiation. For each climate, the calculations were made for the entire heating period. As a result, temperature distributions in a wall at different times of the process and the energy balance of the wall in particular months and during the entire heating period were obtained.
\end{abstract}

\section{Introduction}

Energy requirements that buildings and their elements are subject to have been changing rapidly in recent years. On one hand, this is a result of a strong worldwide focus on energy saving; on the other, this involves increasingly high expectations of users in terms of thermal comfort in buildings.

Accumulating solar walls with transparent insulation (ASW-TI) are becoming a more common project option for new low-energy buildings and renovations of passive buildings [2]. The use of a passive solar wall is aimed at collecting solar energy in order to reduce energy consumption in traditional thermal insulation. This wall stores heat when sunlight is received and returns it with a time lag.

A transparent material is characterized by high solar radiation transmittance and low infrared losses. These materials were developed in order to increase solar radiation transmittance and to enhance thermal resistance of wall systems. In this case, higher heat losses compared to walls with traditional insulation are compensated by heat gains, while the accumulating solar wall acts a heat source in a room. An overview of materials used to make transparent insulation and insulation systems using transparent materials may be found in the following publications $[3,4,5]$.

Factors that affect thermal efficiency of ASW-TI may be divided into two categories. The first category involves parameters associated with location and construction such as shadowing, orientation, material of accumulating wall and its thermal properties; the other category includes climatic conditions, in particular intensity of solar radiation and ambient air temperature.

\footnotetext{
* Corresponding author: j.swirska@po.opole.pl
} 
In order to analyze the effect of the changes to project parameters on thermal efficiency of accumulating solar walls, sensitivity analysis is performed. Numerical simulations are the most commonly used methods for analyzing the efficiency and sensitivity of solar thermal walls $[3,6]$. The [7] paper reveals a new approach to sensitivity analysis by making use of regression analysis. Different approximate methods and calculation models are used to simulate the operation of walls with a transparent insulation layer. Walls of this type may be modelled dynamically in long periods as a part of a building or room in which they are located [8]. Simplified stationary algorithms are used to carry out an approximate evaluation of the impact of walls with transparent insulation on the energy balance of a building [2, 9]. A simplified model based on electrical analogies and the finite-difference method may be used to perform a brief analysis of non-stationary heat transfer in a wall $[1,10]$.

This paper presents a numerical model of an accumulating solar wall with transparent insulation. The objective of the simulation was to evaluate the energy efficiency of ASW-TI for different climatic conditions in Poland, i.e. for high, medium, and low irradiation.

The calculations were made on the basis of the finite-difference method. For each climate, the simulation was carried out for the entire heating period (from September to May). As a result, temperature distributions in a wall at different times of the process and the energy balance of the wall in individual heating period months and during the entire heating period were obtained.

\section{Climatic data}

Intensity of solar radiation (solar irradiance) refers to a instantaneous value of power density of solar radiation, i.e. the power per unit area (perpendicular to the direction of radiation) received from the Sun in the form of electromagnetic radiation. It is usually given in $\left[\mathrm{W} / \mathrm{m}^{2}\right]$. Irradiation (radiance exposure, insolation) is a parameter widely used to describe radiation intensity. It refers to the solar radiation energy per unit area and is calculated by integrating solar irradiance over time (over an hour, month, or a year) [11]. Irradiation is given in units of energy per unit area [e.g. $\left.\mathrm{kWh} / \mathrm{m}^{2}\right]$.

In Poland the average annual irradiation on a horizontal surface is between 950-1150 $\mathrm{kWh} / \mathrm{m}^{2}$. The highest solar irradiation is in June (it is $160 \mathrm{kWh} / \mathrm{m}^{2}$ in Warsaw). The lowest solar irradiation is in December (the average monthly solar irradiation is $11 \mathrm{kWh} / \mathrm{m}^{2}$ ). Only $20 \%$ of the total annual radiation is available between October and March [12].

Solar radiation, its distribution over time, and its availability in different locations are crucial for determining the efficiency of walls with transparent insulation and solar equipment. Although differences in irradiation in Poland are rather small, areas with higher and lower annual irradiation may be distinguished. The highest solar irradiation is found in southern and southeastern Poland, whereas the lowest irradiation is observed in northern Poland.

This paper analyses the efficiency of transparent insulation installed on the southern wall of the building located in three optional places, i.e. in Racibórz, Opole and Szczecinek. The annual irradiation on a horizontal surface in these three places was as follows [13]: Racibórz - $1086 \mathrm{kWh} / \mathrm{m}^{2}$, Opole - $1014 \mathrm{kWh} / \mathrm{m}^{2}$, Szczecinek - $838 \mathrm{kWh} / \mathrm{m}^{2}$. The comparison of the solar irradiation on a horizontal surface in particular heating period months for the locations in question is shown in Figure 1. 


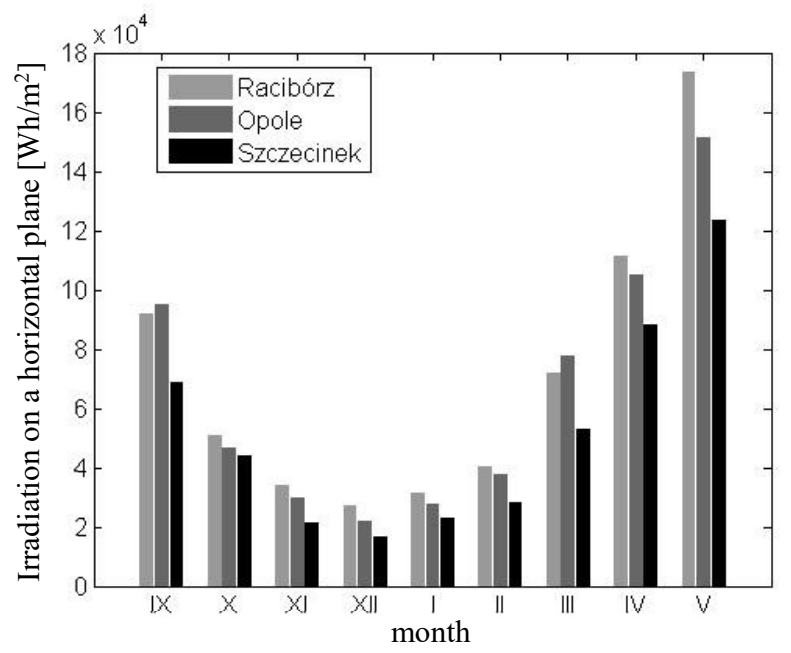

Fig. 1. The irradiation on a horizontal plane in particular months of the heating season.

A data set of hourly meteorological values for a 1-year period, which is characteristic of the climate in a given location and referred to as a typical meteorological year, was used as input data for calculation purposes. These data are available on the Ministry of Infrastructure website [14] in the section concerning energy performance certificates of buildings and they contain climatic figures for Poland. The parameters used in this paper concern hourly values of outdoor temperature (expressed in ${ }^{\circ} \mathrm{C}$ ) and solar irradiance (expressed in $\mathrm{W} / \mathrm{m}^{2}$ ) on a vertical surface oriented south in particular months of heating period for the locations in question. For example, the graphs of these values for Opole are given in Figures 2 and 3.

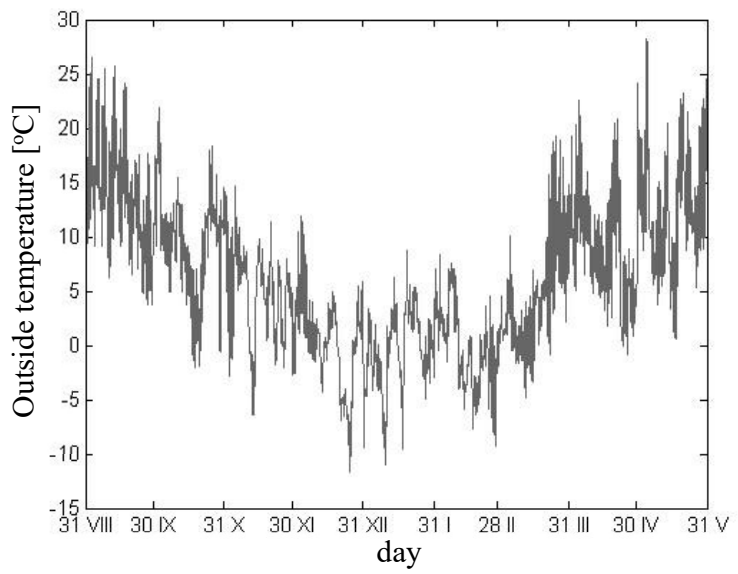

Fig. 2. The outside temperature in Opole during the heating period. 


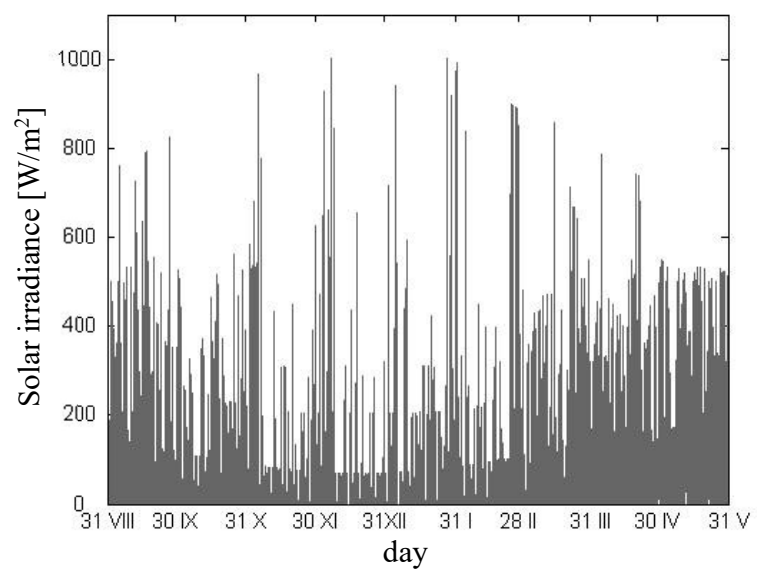

Fig. 3. The intensity of solar radiation falling on the vertical plane in Opole during the heating period.

\section{Mathematical model}

The analyzed problem involves non-stationary and one-dimensional heat transfer with a source at the location of an absorber. This problem may be described by the following set of differential equations:

- thermal conduction equation

$$
\rho c \frac{\partial T}{\partial t}=\lambda \frac{\partial^{2} T}{\partial x^{2}}+Q_{s o l} \quad Q_{s o l}=\frac{\alpha_{s o l, a b s} \tau_{T I} I_{s o l}}{d}
$$

- boundary conditions on the inner and outer surface of the wall

$$
\begin{gathered}
-\lambda \frac{\partial T}{\partial x}=\beta_{e}\left(T(0, t)-T_{e}(t)\right) \\
-\lambda \frac{\partial T}{\partial x}=\beta_{i}\left(T_{i}-T(l, t)\right)
\end{gathered}
$$

- initial condition

$$
T(x, 0)=T_{o}(x)
$$

where: $T$-temperature $\left[{ }^{\circ} \mathrm{C}\right], \rho$-density of the material $\left[\mathrm{kg} / \mathrm{m}^{3}\right], c$ - specific heat $[\mathrm{J} /(\mathrm{kg} \cdot \mathrm{K})]$, $\lambda$ - thermal conductivity $[\mathrm{W} /(\mathrm{m} \cdot \mathrm{K})], x$ - spatial coordinate $[\mathrm{m}], t$ - time $[\mathrm{s}], Q_{\text {sol }}$ - heat source in the wall (where the absorber is located) $\left[\mathrm{W} / \mathrm{m}^{3}\right], \alpha_{\text {sol,abs }}-$ coefficient of solar radiation absorption by the absorber (usually higher than 0.9 ) [-], $\tau_{T I}$ - coefficient of total solar energy transmittance of transparent insulation [-], $I_{\text {sol }}$ - total solar irradiance on the wall surface $\left[\mathrm{W} / \mathrm{m}^{2}\right], d$ - thickness of the absorber (part of the wall that absorbs solar radiation) $[\mathrm{m}], \beta$ - convective heat transfer coefficient $\left[\mathrm{W} /\left(\mathrm{m}^{2} \cdot \mathrm{K}\right)\right], T_{o}$ - initial temperature $\left[{ }^{\circ} \mathrm{C}\right], l$ - wall thickness $[\mathrm{m}]$, subscripts $e, i$ - exterior, interior.

For simplification, in the above equations it was given that all coefficients in the model are constant and the absorptivity of solar radiation by transparent insulation is negligibly small. Radiation heat transfer between the absorber surface and the inner surface of transparent insulation, between which there is usually an air gap, was also omitted.

In the subject literature concerning differential expressions for the issues in question, the elementary balances $[8,12]$ or electric network analogue method $[1,10]$ is usually used to 
develop a numerical model of the analyzed issue. In this paper, a discreet model of the issue was obtained directly by equation (1-3) discretization using right-hand difference quotients for time discretization and central quotients for spatial derivatives. Based on the above, an explicit finite difference scheme was developed, in which temperatures at individual points in the next time step $T_{i, j+1}$ are determined directly on the basis of the temperatures from the previous step [15]. Having considered that it is a multi-layer medium, discretized equations take the following form

$$
\begin{gathered}
\frac{\rho_{i} c_{i}+\rho_{i+1} c_{i+1}}{2} \frac{T_{i, j+1}-T_{i, j}}{\Delta t}=\frac{2 \lambda_{i+1}}{\Delta x_{i+1}\left(\Delta x_{i}+\Delta x_{i+1}\right)}\left(T_{i+1, j}-T_{i, j}\right)+ \\
-\frac{2 \lambda_{i}}{\Delta x_{i}\left(\Delta x_{i}+\Delta x_{i+1}\right)}\left(T_{i, j}-T_{i-1, j}\right)+Q_{s o l, i, j} \\
\lambda_{0} \frac{T_{1, j}-T_{-1, j}}{2 \Delta x_{i}}=\beta_{e}\left(T_{0, j}-T_{z, j}\right) \rightarrow T_{-1, j}=-\frac{2 \beta_{e} \Delta x_{i}}{\lambda_{0}}\left(T_{0, j}-T_{e, j}\right)+T_{1, j} \\
\lambda_{n} \frac{T_{n+1, j}-T_{n-1, j}}{2 \Delta x_{n}}=\beta_{i}\left(T_{i, j}-T_{n, j}\right) \rightarrow T_{n+1, j}=\frac{2 \beta_{i} \Delta x_{i}}{\lambda_{0}}\left(T_{i, j}-T_{n, j}\right)+T_{n-1, j}
\end{gathered}
$$

where subscripts $i$ and $j$ refer to spatial and time discretization respectively, $n$ refers to the number of nodes in the wall, subscripts -1 and $n+1$ refer to fictitious nodes.

In case of the explicit finite difference scheme, there is a limit on the time step length $\Delta t$. The condition for algorithm convergence is the coefficient in equation (5) near $T_{i, j}$ being positive. Therefore, when $\Delta x_{i}$ is constant, the following condition is obtained

$$
1-\frac{\Delta t}{\rho_{i} c_{i}}\left(\frac{\lambda_{i}+\lambda_{i+1}}{(\Delta x)^{2}}\right) \geq 0 \rightarrow \Delta t \leq \frac{\rho_{i} c_{i}(\Delta x)^{2}}{\lambda_{i}+\lambda_{i+1}}
$$

\section{Calculation results}

The ASW-TI wall in question consists of the following elements:

- transparent insulation (cellulose acetate with the honeycomb structure + double glazing), thickness $108 \mathrm{~mm}$, total solar energy transmittance 0.56 , and thermal conductivity $0.8 \mathrm{~W} /\left(\mathrm{m}^{2} \cdot \mathrm{K}\right)$;

- non-ventilated air gap with a thickness of $20 \mathrm{~mm}$;

- Silka blocks, thickness $240 \mathrm{~mm}$; density $1800 \mathrm{~kg} / \mathrm{m}^{3}$, specific heat $880 \mathrm{~J} /(\mathrm{kg} \cdot \mathrm{K})$, thermal conductivity $0.65 \mathrm{~W} /(\mathrm{m} \cdot \mathrm{K})$, and solar radiation absorption coefficient 0.91 ;

- cement and lime plaster with a thickness of $12 \mathrm{~mm}$.

When modelling the wall, insulation glazing and transparent insulation itself were considered separate layers. Therefore, the wall was divided into $4 \mathrm{~mm}$ thick layers. The use of a $0.09 \mathrm{~s}$ time step was necessary. It was also assumed that the solar heat flux that reaches the wall through transparent insulation is absorbed by a layer of calcium silicate blocks with a thickness of $\Delta x(d=4 \mathrm{~mm})$.

There is a problem with the initial condition in the case in question because the temperature distribution in the wall at the initial time is unknown. Thus, the first approximation involved a homogeneous boundary condition $\left(T_{\mathrm{o}}=20^{\circ} \mathrm{C}\right)$, and for the first twenty-four hours (1 September) calculations were repeated until a repeatable temperature variation was obtained during the day in the external conditions corresponding to that 24hour period. Having an accuracy of up to $0.001^{\circ} \mathrm{C}$, that condition was obtained after ten 24- 
hour periods. The temperature distribution obtained in this manner was considered the initial condition for calculations over the entire heating period. The authors of the paper used the Matlab environment to develop a program that calculated necessary values.

As a result of the calculations, temperature distributions in the wall at individual times of the heating period were obtained for climatic conditions in Racibórz, Opole and Szczecinek. Figures 4-6 demonstrate examples of graphs with a daily wall temperature variation for the Opole building in January when the weather during the day was sunny $\left(I_{\text {sol,max }}=1001 \mathrm{~W} / \mathrm{m}^{2}\right)$, partly cloudy $\left(I_{\text {sol, } \max }=543 \mathrm{~W} / \mathrm{m}^{2}\right)$ and cloudy $\left(I_{\text {sol, } \max }=72 \mathrm{~W} / \mathrm{m}^{2}\right)$ respectively 4-6.

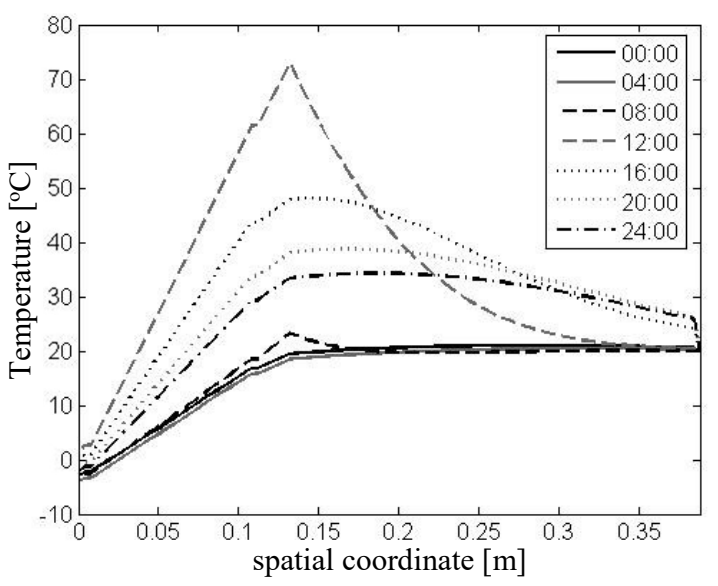

Fig. 4. Daily temperature changes of the partition on a sunny January day.

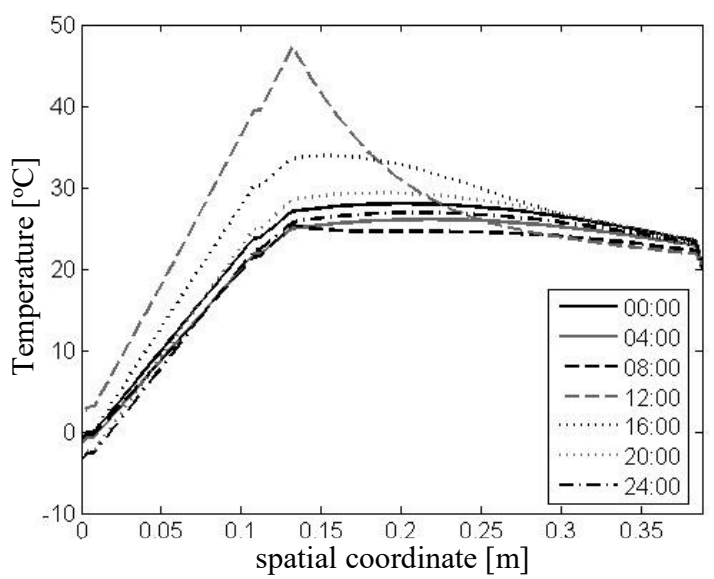

Fig. 5. Daily temperature changes of the partition in January day with moderate cloud cover.

As a result of the calculations, the energy balance of the wall in particular heating period months and during the entire heating period was also obtained for the three building locations in question. The energy balance was achieved by integrating heat flux on the inner wall surface over time. The results are shown in Figure 7 and presented in table form in Table 1. 


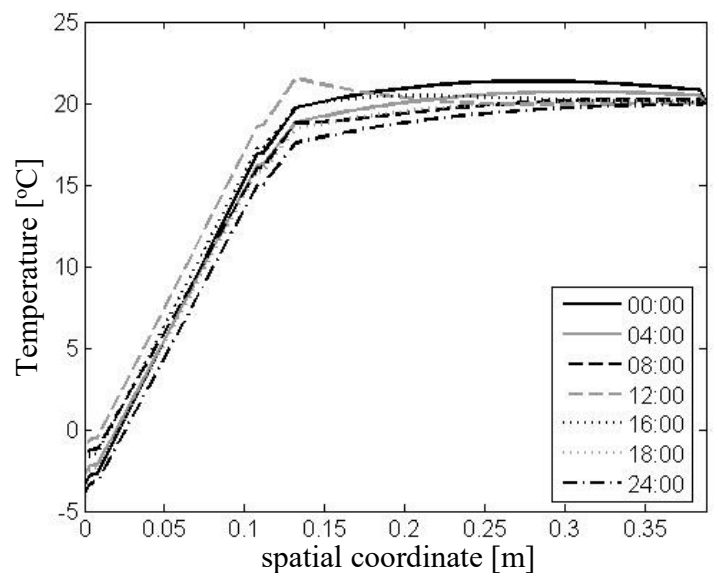

Fig. 6. Daily temperature changes of the partition on a cloudy January.

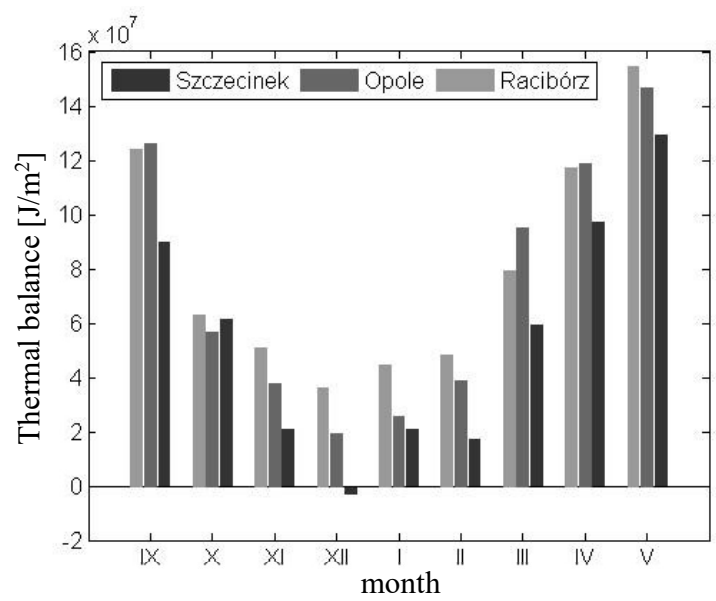

Fig. 7. Thermal balance of the partition in particular months of the heating season.

Table 1. Thermal balance of the partition in particular months of the heating season.

\begin{tabular}{|c|c|c|c|}
\hline \multirow{2}{*}{ Month } & \multicolumn{3}{|c|}{ Thermal balance of the partition $\left[\mathrm{kWh} / \mathrm{m}^{2}\right]$} \\
\cline { 2 - 4 } & Racibórz & Opole & Szczecinek \\
\hline September & 34.48 & 35.05 & 24.99 \\
\hline October & 17.40 & 15.75 & 16.97 \\
\hline November & 14.14 & 10.49 & 5.72 \\
\hline December & 10.05 & 5.37 & $\mathbf{- 0 . 7 9}$ \\
\hline January & 12.29 & 7.05 & 5.78 \\
\hline February & 13.43 & 10.80 & 4.77 \\
\hline March & 21.96 & 26,44 & 16.41 \\
\hline April & 32.58 & 33.00 & 27.04 \\
\hline May & 42.90 & 40.70 & 35.90 \\
\hline Sum & 199.24 & 184.65 & 136.79 \\
\hline
\end{tabular}




\section{Conclusions}

The calculations show that in case of all locations analyzed, the energy balance of the wall with transparent insulation is positive for most of the heating period months. For the wall in the Szczecinek building, the energy balance of the wall was only negative in December. This means that in case of almost all months, regardless of the location in Poland, the wall acts as a source of heat in the room and contributes to reducing heat demand.

Assuming that the analyzed wall with transparent insulation took up $15 \mathrm{~m}^{2}$ of the southern elevation, it would generate heat gains within a year as follows: in Racibórz - 2988.6 kWh, in Opole - $2769.7 \mathrm{kWh}$, and in Szczecinek - $2051.9 \mathrm{kWh}$. If the wall was installed in a detached house with the usable area of $120 \mathrm{~m}^{2}$, the internal heat gains, calculated according to the Regulation method [16], would be $5346.4 \mathrm{kWh}$ within a year. Therefore, solar gains achieved due to transparent insulation within the period in question would amount to $55.9 \%$, $51.8 \%$, and $38.4 \%$ of the value of internal heat gains respectively.

To sum up, it may be concluded that walls with transparent insulation are also useful in Poland. However, their main disadvantage is still their expensiveness and the fact that they generate lower heat gains in winter, i.e. exactly when heat losses are highest and when such gains would be most desirable.

\section{References}

1. Kisilewicz T., Archives of Civil and Mechanical Engineering, IX, 1 (2009)

2. M. Ochs, A. Heller, H.H. Simmler, Proceedings of the 3rd Int. ISES Europe Solar Congress „Eurosun 2000”, Copenhagen, Denmark (2000)

3. N.D. Kaushikaa K., Sumathyb, Renewable and Sustainable Energy Reviews, 7, 4 (2003)

4. I.L.Wonga, P.C. Eamesb, R.S. Perera, Solar Energy, 81, 9 (2007)

5. Y. Sun, PhD thesis of University of Nottingham (2017)

6. H.X. Yang, Z.L. Zhu, J. Burnett, Applied Energy, 67 (2000)

7. X. Fang, T. Yang, Applied Thermal Engineering, 28, 17-18 (2008)

8. H. Koczyk, A. Górka, M. Basińska, Modern Building Materials, Structures and Techniques, The 7th International Conference, Vilnius (2001)

9. A. Machniewicz, A. Borowczyński, D. Heim, Technical Transactions Civil Engineering 3-B (2014)

10. A.K. Athienitis, H. Ramadan, Solar Energy, 67, 1-3, (1999)

11. D. Chwieduk, Solar energy in buildings: thermal balance for efficient heating and cooling (Elsevier 2014)

12. D. Chwieduk, Polish J. of Enviro. Stud., 19, 3 (2010)

13. P. Narowski, Rynek Instalacyjny 10/2008 (2008)

14. mib.gov.pl/2

15. J. Szargut, Metody numeryczne w obliczeniach cieplnych pieców przemystowych (Wyd. Śląsk 1977)

16. Rozporządzenie Ministra Infrastruktury i Rozwoju z dnia 27 lutego 2015 r., Dz.U. 2015 poz. 376 